\title{
Image processing algorithm to assess the roundness of blanks for the production of copper seals for brake, fuel and gas installations
}

\author{
Algorytm przetwarzania obrazu w celu oceny okrągłości \\ półfabrykatów do wytwarzania miedzianych uszczelnień \\ instalacji hamulcowych, paliwowych i gazowych
}

\author{
MICHAL BATSCH \\ WALDEMAR WITKOWSKI \\ DAWID WYDRZYŃSKI*
}

DOI: https://doi.org/10.17814/mechanik.2021.7.10

\begin{abstract}
The possibilities of the vision system for the assessment of the shape of semi-finished products for the production of copper seals for fuel installations in the automatic production process were analyzed. The used vision system was presented and an algorithm was developed to assess the roundness of manufactured semi-finished products. The paper presents the results of an experiment conducted on a designed and constructed test stand. The experiment aimed at demonstrating the suitability of the method for analysis of roundness deviation of parts.

KEYWORDS: roundness assessment, vision system, copper seals
\end{abstract}

Przeanalizowano możliwości systemu wizyjnego służącego do oceny kształtu półwyrobów do produkcji miedzianych uszczelnień instalacji paliwowych $\mathrm{w}$ automatycznym procesie wytwarzania. Zaprezentowano stosowany system wizyjny oraz opracowano algorytm do oceny okrągłości wytwarzanych półfabrykatów. Przedstawiono wyniki eksperymentu prowadzonego na zaprojektowanym i wykonanym stanowisku badawczym. Eksperyment miał na celu wykazanie przydatności metody do analizy odchyłki okrągłości detali.

SŁOWA KLUCZOWE: ocena okrągłości, system wizyjny, uszczelnienia miedziane

\section{Wprowadzenie}

Systemy wizyjne w przemyśle maszynowym są stosowane m.in. do oceny cech fizycznych wyrobów w procesie produkcyjnym [1]. Analizowane cechy to m.in.: kształt elementu, jego kolor i stan powierzchni. Współczesne systemy wizyjne pracują bardzo szybko, co znacząco skraca czas inspekcji.

W niniejszej pracy przeanalizowano możliwości wykorzystania systemu wizyjnego do oceny kształtu półwyrobów do produkcji miedzianych uszczel- nień instalacji hamulcowych, paliwowych i gazowych w procesie automatycznym. Uszczelnienia tego typu są wykrawane z okrągłych półwyrobów. Aby zminimalizować straty materiałowe, odpady stanowiące środkową część elementów są przetwarzane na półfabrykaty do wyrobu kolejnych uszczelnień, np. o mniejszej średnicy. Na tym etapie produkcji zachodzi konieczność kontroli półfabrykatów oraz podjęcia decyzji o możliwości ich dalszego przetwarzania. Końcowy produkt musi bowiem spełniać warunki okrągłości oraz być wolny od rys, a to z kolei zależy bezpośrednio od wykorzystanego w produkcji półfabrykatu.

\section{Algorytm przetwarzania obrazu}

Do weryfikacji opracowanego algorytmu wykorzystano system wizyjny firmy Keyence złożony z:

- kameryCA-200Co rozdzielczości 1600 px × 1200 px, - soczewek CA-LH35 (odległość montażowa od detalu do końca soczewki ok. 250 mm [2]),

- oświetlacza pierścieniowego LED CA-DRW9 (montowanego w odległości ok. $100 \mathrm{~mm}$ od detalu).

W wyniku kalibracji uzyskano współczynnik skali $c=0,0322 \mathrm{~mm} / \mathrm{px}$. Na tak skonfigurowanym stanowisku przeprowadzono próby oceny dokładności geometrycznej półwyrobów.

Schemat blokowy opracowanego algorytmu wraz z przykładem zastosowania przedstawiono na rysunku.

Algorytm rozpoczyna się od wczytania zarejestrowanego obrazu mierzonego detalu (2). Zostaje on przekonwertowany na obraz binarny (3) z wykorzystaniem wartości progowej większej od wyznaczonej metodą opisaną w [3]. Po usunięciu szumów (4) puste przestrzenie zostają wypełnione w wyniku operacji morfologicznych (5). Kolejnym etapem jest ponowne usunięcie szumów (6). Oryginalny obraz jest po raz kolejny konwertowany na

\footnotetext{
* Dr inż. Michał Batsch, mbatsch@prz.edu.pl, https://orcid.org/0000-0001-5243-2604 - Politechnika Rzeszowska, Rzeszów, Polska Dr inż. Waldemar Witkowski, wwitkowski@prz.edu.pl, https://orcid.org/0000-0002-0400-0011 - Politechnika Rzeszowska, Rzeszów, Polska

Dr inż. Dawid Wydrzyński, dwydrzynski@prz.edu.pl, https://orcid.org/0000-0002-1403-9809 - Politechnika Rzeszowska, Rzeszów, Polska
} 


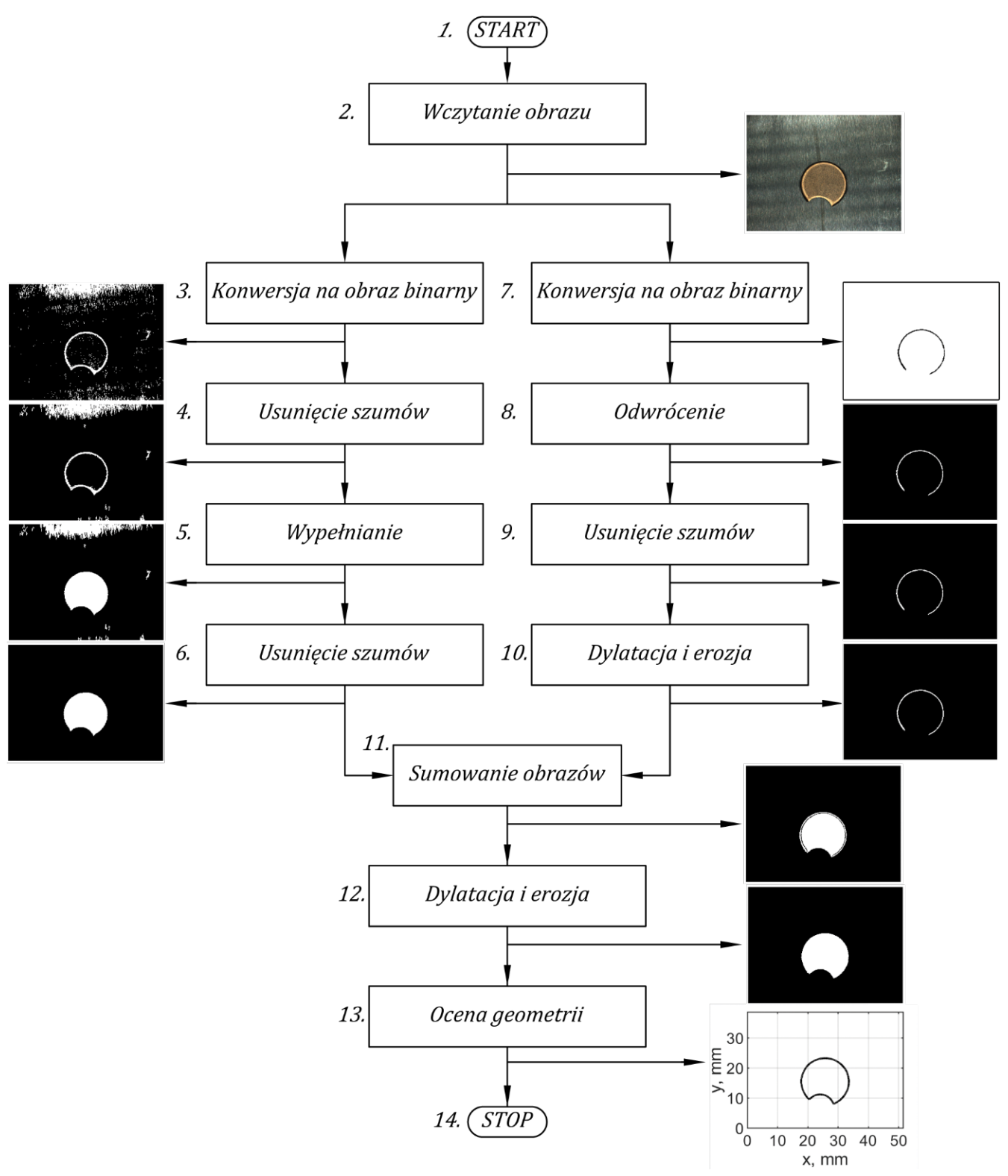

Fig. Block diagram of the algorithm Rys. Schemat blokowy algorytmu

obraz binarny, przy czym użyta wartość progowa jest mniejsza niż wartość obliczona metodą opisaną w [3] (7). Następnie zostaje on odwrócony (8), a ewentualne szumy zostają usunięte (9). Kolejne etapy to dylatacja i erozja (10). Tak uzyskane obrazy są sumowane (11) i ponownie przeprowadza się operacje dylatacji i erozji (12). Mają one na celu wypełnienie pustych przestrzeni oraz wygładzenie krawędzi zewnętrznej obszaru, która reprezentuje zarys mierzonego przedmiotu. Uzyskany obszar, a zwłaszcza jego kontur, po przeskalowaniu można wyeksportować $\mathrm{w}$ postaci zbioru punktów $x_{\mathrm{i}}, y_{\mathrm{i}}$ (gdzie $\left.i=1,2, \ldots, n\right)$ do dalszej oceny geometrycznej (13). Ocena geometryczna polega na sprawdzeniu okragłości detalu. W tym celu punkty pomiarowe są aproksymowane okręgiem wyznaczanym metodą najmniejszych kwadratów. Zagadnienie to sprowadza się do problemu optymalizacyjnego $\mathrm{w}$ postaci:

$$
\sum_{i=1}^{n} f_{\mathrm{i}}^{2}(\boldsymbol{a})=\min
$$

gdzie: $f_{\mathrm{i}}(\boldsymbol{a})=\left(x_{\mathrm{i}}-a_{1}\right)^{2}+\left(y_{\mathrm{i}}-a_{2}\right)^{2}-a_{3}^{2}$ to funkcja błędu; $\boldsymbol{a}=\left\{a_{1}, a_{2}, a_{3}\right\}$ to wektor parametrów poszukiwanego okręgu, przy czym $a_{1}, a_{2}$ to współrzędne środka okręgu, a $a_{3}$ to jego promień.

Problem (1) można rozwiązać w sposób numeryczny, np. z wykorzystaniem algorytmów typu trust-region [4] lub algorytmu zaproponowanego w pracach [5-6]. Błąd okrągłości $t$ wyznacza się jako różnicę odległości maksymalnej i minimalnej punktów pomiarowych od środka okręgu aproksymującego:

$$
\begin{aligned}
t & =\max \left(\sqrt{\left(x_{\mathrm{i}}-a_{1}\right)^{2}+\left(y_{\mathrm{i}}-a_{2}\right)^{2}}\right)- \\
& -\min \left(\sqrt{\left(x_{\mathrm{i}}-a_{1}\right)^{2}+\left(y_{\mathrm{i}}-a_{2}\right)^{2}}\right)
\end{aligned}
$$

W tablicy przedstawiono wyniki kilku przypadków oceny dokładności geometrycznej wyrobów. 
TABLE. The results of the assessment of geometric accuracy TABLICA. Wyniki oceny dokładności geometrycznej

Oryginalny obraz
z wykrytym konturem

Czas analizy obrazu w każdym z zaprezentowanych przykładów nie przekroczył 0,5 s, przy czym obliczenia były realizowane na komputerze klasy notebook z procesorem Intel ${ }^{\circledR} \mathrm{Core}^{\mathrm{TM}} \mathrm{i} 7-3820 \mathrm{QM} 2.70 \mathrm{GHz}$, pamięcia 32 GB RAM i 64-bitowym systemem operacyjnym Windows 10 Pro. Największy zarejestrowany błąd okrągłości wyniósł 3,56 mm, a najmniejszy: $0,22 \mathrm{~mm}$.

\section{Wnioski}

Na podstawie przeprowadzonych badań stwierdzono, że zaprezentowany algorytm wraz z dobranym systemem wizyjnym może posłużyć do oceny okrągłości półfabrykatów w przypadku automatycznej produkcji uszczelnień miedzianych. Uzyskany czas przetwarzania obrazu pozwoli na inspekcję z prędkością na poziomie ok. 2 szt./s, przy czym przyszłe zastosowanie specjalnego układu mikroprocesorowego może znaczenie zwiększyć tę prędkość.

\section{Finansowanie}

-00-0630/19, realizowanego w ramach działania 1.1 „Projekty B+R przedsiębiorstw”, poddziałanie 1.1.1 „Badania przemysłowe i prace rozwojowe realizowane przez przedsiębiorstwa", współfinansowanego z Programu Operacyjnego Inteligentny Rozwój.

Fundusze Europejskie

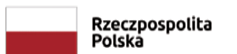<smiles>C=[GeH]</smiles>
Unia Europejska

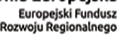

\section{$\cdots$}

[1] Silva R.L., Rudek M., Szejka A.L., Junior O.C. "Machine Vision Systems for Industrial Quality Control Inspections" in: Chiabert P., Bouras A., Noël F., Ríos J. (red.). "Product Lifecycle Management to Support Industry 4.0". Cham: Springer International Publishing, 2018: pp. 631-641. https:// doi.org/10.1007/978-3-030-01614-2_58.

[2] Keyence. Vision System Peripheral Equipment. CA Series. Version 7.

[3] Otsu N. "A Threshold Selection Method from Gray-Level Histograms". IEEE Transactions on Systems, Man, and Cybernetics. 9 (1979): 62-66.

[4] Nocedal J., Wright S. "Numerical Optimization". wyd. 2. New York: Springer-Verlag, 2006, https://doi.org/ 10.1007/ 978-0-387-40065-5.

[5] Levenberg K. "A Method for the Solution of Certain Problems in Least Squares". Quarterly of Applied Mathematics. 2 (1944): 164-168.

[6] Marquardt D.W. "An algorithm for least-squares estimation of nonlinear parameters". Journal of the Society for Industrial and Applied Mathematics. 11 (1963): 431-441, https://doi.org/10.1137/0111030. 